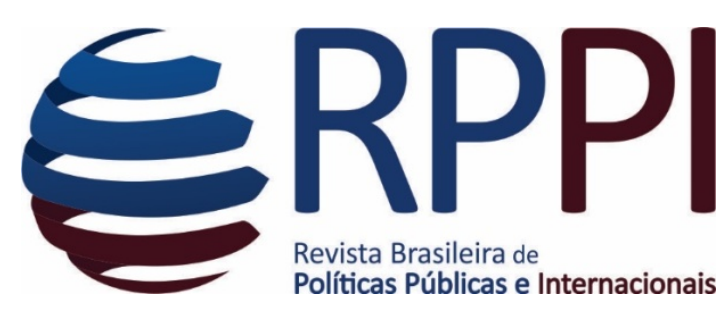

Data de recebimento: 06/02/2018

Data de aceite: 07/08/2018

Organização: Programa de Pós-Graduação em

Gestão Pública e Cooperação Internacional

(PGPCI/UFPB)

Avaliação: Por Pares.

\title{
Reflexiones en torno a la Nueva Cooperación China para la Transformación Estructural: contrastes y tensiones con el Régimen de Cooperación Internacional para el Desarrollo tradicional
}

\section{Reflexões em torno Nova Cooperação Chinesa para a Transformação Estrutural: contrastes e tensões com o regime tradicional de cooperação internacional para o desenvolvimento}

\section{Reflections on the new Development Cooperation for Structural Transformation: tensions and contrasts with the traditional international cooperation for development}

\author{
Aldo Dominguez \\ Centro de Estudios del Desarrollo Económico y Social (CEDES), Benemérita Universidad \\ Autónoma de Puebla \\ E-mail: aldo.domin@outlook.com \\ Giuseppe Lo Brutto \\ Benemérita Universidad Autónoma de Puebla \\ E-mail: giuseloby@msn.com
}

\begin{abstract}
Resumo: O atual regime de cooperação internacional para o desenvolvimento atravessa por profundas mudanças derivadas tanto dos fracassos acumulados desde a sua criação até os dias de hoje quanto pelos desafios do papel predominante da República Popular China (RPCh) nas relações políticas e económicas internacionais. O propósito deste artigo é apresentar a Nova Cooperação Chinesa para a Transformação Estrutural e, ao mesmo tempo, salientar os contrastes e tensões com o regime tradicional de Cooperação Internacional para o Desenvolvimento.
\end{abstract}

Palavras chave: Cooperação Internacional para o Desenvolvimento, Nova Cooperação para a transformação estrutural, China, Cooperação Sul-Sul.

Resumen: El régimen actual de Cooperación Internacional para el Desarrollo vive profundos cambios derivados tanto de los fracasos que lo han caracterizado desde su creación hasta la fecha como por el cada vez más predominante papel que la República Popular China (RPCh) ha ido desarrollando en los entramados de las relaciones políticas y económicas internacionales. El propósito de este artículo es poner en evidencia en que consiste la Nueva Cooperación China para la Transformación Estructural y al 
DOMINGUEZ, Aldo; LO BRUTTO, Giuseppe. Reflexiones en torno a la Nueva Cooperación China para la Transformación Estructural: contrastes y tensiones con el Régimen de Cooperación Internacional para el Desarrollo tradicional.

mismo tiempo resaltar los contrastes y las tensiones con el régimen de Cooperación Internacional para el Desarrollo tradicional.

\title{
Palabras Claves
}

Cooperación Internacional para el Desarrollo; Nueva Cooperación para la Transformación Estructural; China, Cooperación Sur-Sur.

\begin{abstract}
The current international cooperation of development has seen profound changes stemming as much from its characteristic failures, which have been present from the program's creation through today, as from the Popular Republic of China's ever increasing role in the development of intertwined political and international economic relationships. The purpose of the article is to show what the new Development Cooperation for Structural Transformation actually consists of and at the same time to shine a light on the tensions and contrasts with the traditional International cooperation for development.
\end{abstract}

Keywords: International cooperation for development; new Development Cooperation for Structural Transformation; China; South-South Cooperation.

\section{Introducción}

Ante la complejidad que implica el análisis de la cooperación al desarrollo, parecen haber surgido dos formas desde las cuales se puede observar. La primera de ellas, se realiza a nivel de «suelo», donde el objeto principal de estudio es la dinámica y los involucrados de lo que se conoce como ayuda al desarrollo o ayuda internacional, es decir, el foco de atención está dirigido a la métrica, gramática y los actores de la llamada industria de la ayuda; la otra, presenta un análisis desde una perspectiva «cenital» en donde la cooperación internacional, es una pieza que conforma el sistema internacional en su totalidad, concentrando sus estudios en la dinámica de la cooperación, incluida el tema de la ayuda (Benzi \& Lo Brutto, 2013).

Al mismo tiempo existen dos perspectivas principales sobre las cuales se vislumbra la cooperación al desarrollo. Esta se determina de acuerdo al sistema de cooperación que se pretenda observar, lo que influirá en la visión misma de la cooperación y los elementos que la conforman. La primera, enfocada al régimen tradicional de cooperación, donde la Ayuda

Revista Brasileira de Políticas Públicas e Internacionais, v.3, n.2, Dezembro/2018, pp. 81-99. 
DOMINGUEZ, Aldo; LO BRUTTO, Giuseppe. Reflexiones en torno a la Nueva Cooperación China para la Transformación Estructural: contrastes y tensiones con el Régimen de Cooperación Internacional para el Desarrollo tradicional.

Oficial al Desarrollo (AOD) ha sido trabajada por casi setenta años para disponer de una estructura institucionalizada. Además de poseer definiciones estrictas a través su gramática, métrica y actores, que han venido evolucionando desde aquel punto IV de Truman donde se cimentaría este régimen de cooperación. La segunda perspectiva corresponde al sistema de Cooperación Sur-Sur (CSS) en el que los países en desarrollo han invertido mayores esfuerzos en la dinámica de cooperación, que a la definición u organización de sí misma. Llegando a considerar cualquier emprendimiento de carácter transversal entre países en vías de desarrollo, esto por el amplio espectro de la definición de cooperación en este sistema.

Dicho lo anterior, la CSS ha presentado un aumento de su peso político en el sistema internacional, alcanzado gracias al ascenso geopolítico de los $\mathrm{BRICs}^{1}$, donde China se ha perfilado como el principal promotor. Es importante observar que, con la presencia del país asiático, la CSS parece dar un giro hacia un objetivo más allá que la cooperación para el desarrollo tradicional. Efectivamente, China encuentra en la CSS una herramienta de influencia, la cual le sirve de apalancamiento en su escalada para posicionarse en la cúspide de la hegemonía, y, a través de la cooperación internacional promueve un cambio de estructura de la economía mundial.

La teorización de dicha cooperación como un instrumento para la transformación estructural, bajo una lógica geoestratégica vinculada a la reconfiguración del orden internacional, se apoya en las ideas de Justin Yifu Lin $^{2}$, sobre el industrial upgrading y de una gran especialización de la cooperación china a través de megaproyectos de infraestructura con financiación concesional atada (Domínguez, 2017). Desde esta perspectiva, la República Popular China (RPCh) se perfila al posicionamiento hegemónico mundial comenzando a mover los engranajes para lograr una transformación y resignificar a la cooperación en sí (Xuetong, 2016). Por lo tanto, ante un sistema de AOD que se encuentra en crisis, gracias a la

\footnotetext{
${ }^{1}$ Brasil, Rusia, India, China y Sur África.

${ }^{2}$ Originario de Taiwán, quien entre 2008 y 2012 fue vicepresidente del Banco Mundial.
}

Revista Brasileira de Políticas Públicas e Internacionais, v.3, n.2, Dezembro/2018, pp. 81-99. 
DOMINGUEZ, Aldo; LO BRUTTO, Giuseppe. Reflexiones en torno a la Nueva Cooperación China para la Transformación Estructural: contrastes y tensiones con el Régimen de Cooperación Internacional para el Desarrollo tradicional.

disminución en las aportaciones sumado al creciente proteccionismo por temas de seguridad y económicos, el gigante asiático ha logrado el suficiente consenso de países para comenzar a transformarlo y a la vez promover e impulsar el propio.

Desde esta visión, el objetivo de este artículo es describir y analizar los elementos que conforman a la cooperación china como una propuesta de sistema de cooperación para el cambio estructural y cómo este coloca en tensión al régimen tradicional de cooperación. Se pretende visualizar la cooperación para el cambio estructural como una contraposición al régimen tradicional de cooperación, el cual tiene como fin reestructurar la dinámica global, dirigido por China y soportado por los países del sur con el incentivo de una oferta alternativa para alcanzar el desarrollo. Esta contraposición ha generado tensiones que han hecho más visibles las deficiencias acumuladas en más de 60 años del régimen de cooperación. Por ello, en la primera parte del documento se trata de explicar y visualizar la cooperación para el cambio estructural y cómo esta se encuentra inmersa en la CSS actual, para después, en el siguiente punto analizar los elementos que llevan a reflexionar la tensión en que se pone al régimen tradicional de cooperación al verse conviviendo con la cooperación para el cambio estructural. Finalmente, en las conclusiones se reflexiona en torno a estos contrastes y a estas diferencias entre dos sistemas de cooperación que conviven en el marco de una nueva reconfiguración hegemónica ${ }^{3}$ que ve su epicentro en la RPCh.

\section{Cooperación para el cambio estructural}

Actualmente por el tamaño que ha alcanzado, China va asumiendo cada vez más responsabilidades con el correcto funcionamiento del sistema global de financiamiento al desarrollo que va más allá de sus propios intereses (Lin \& Wang, 2017). Este dinamismo,

\footnotetext{
${ }^{3}$ Nos referimos al hecho que en la transición hegemónica actual se perfila un período de desorden del sistema internacional en el que el hegemón (en este caso los Estados Unidos) experimenta una pérdida de poder económico y político frente a una potencia en ascenso (China).
}

Revista Brasileira de Políticas Públicas e Internacionais, v.3, n.2, Dezembro/2018, pp. 81-99. 
DOMINGUEZ, Aldo; LO BRUTTO, Giuseppe. Reflexiones en torno a la Nueva Cooperación China para la Transformación Estructural: contrastes y tensiones con el Régimen de Cooperación Internacional para el Desarrollo tradicional.

interés y responsabilidad que ha mostrado el gigante asiático con el tema de la cooperación, Yifu Lin los atribuye a la nueva generación de líderes que han tenido la visión de fortalecer y modernizar los principios de la ayuda exterior china en los últimos 50 años.

El posicionamiento del gigante asiático en la hegemonía mundial no ha sido buscando un enfrentamiento frontal con el contendiente número uno, los Estados Unidos (EE.UU.), ya que, en palabras del presidente Xi Jinping “El basto océano pacífico tiene amplio espacio para China y los EE.UU.” (Lin \& Wang, 2017, p.9). Por lo que la RPCh ha optado por otra estrategia, a través de una campaña pacifica con la que logra una doble participación de las relaciones internacionales en tema de la cooperación al desarrollo ratificando la importancia del régimen tradicional de cooperación al ser miembro activo, y al mismo tiempo emprendiendo la estructuración de su visión de sistema de cooperación. Por ello, complementa su estrategia geopolítica y reestructuración geoeconómica a través de la cooperación.

Además, de acuerdo con la teoría china del realismo moral, el nuevo líder global tendrá que "practicar la ideología de la rectitud, la justicia, la civilidad, tanto en casa como fuera, por el bien de sus propios intereses estratégicos, así como para los del mundo” (Xuetong, 2016, p.26). Por eso, en resumen, una cooperación para el cambio estructural se refiere la estrategia emprendida por China como actor de la cooperación internacional, en la que tiene el objetivo de promover los cambios en la estructura económica de un país receptor a través de la inversión a la infraestructura y cooperación técnica para el aprovechamiento de sectores con ventajas comparativas latentes, a través la realización de una resignificación del desarrollo y de la manera de cómo alcanzarlo. Entendiendo el comercio justo como cooperación al desarrollo, los chinos incentivan la participación del Estado como facilitador de políticas públicas alineadas a este cambio (Lin \& Wang, 2017). De esta forma la RPCh pretende aumentar su influencia en el entramado geopolítico, gracias al cabildeo entre países en desarrollo, conseguido por las atractivas «facilidades» para acceder a este tipo de cooperación lo que le permiten organizar de manera más amplia las redes económicas.

Revista Brasileira de Políticas Públicas e Internacionais, v.3, n.2, Dezembro/2018, pp. 81-99. 
DOMINGUEZ, Aldo; LO BRUTTO, Giuseppe. Reflexiones en torno a la Nueva Cooperación China para la Transformación Estructural: contrastes y tensiones con el Régimen de Cooperación Internacional para el Desarrollo tradicional.

Para impulsar el cambio estructural entre sus socios, China se ha apoyado principalmente del andamiaje construido por la CSS. La cual, desde el punto de vista de la transformación planeada y el aprendizaje conjunto, se ha considerado más eficaz para fines de esta cooperación, debido a la similitud en las etapas de transformación estructural, en sus niveles de desarrollo y en las restricciones institucionales y humanas que poseen los países del Sur (Lin \&Wang, 2017). A esto, se debe agregar que el país asiático opera en los tres pilares de la CSS, el primero, es el diálogo político donde China ha logrado forjar acuerdos intergubernamentales de cooperación; el segundo pilar son los tratados comerciales y de integración, logrados en el diálogo político, los cuales establecen la base operacional con la que inicia el cambio estructural; y, por último, el tercer pilar es la cooperación financiera y técnica, colocándose como la chispa que activa el cambio estructural (Domínguez, 2016).

El acoplamiento de la ayuda China dentro de la CSS parece embonar sin complicaciones. Esto sucede gracias a que China enmarca su identidad entre los países del Sur global, realizando contribuciones importantes a la doctrina de la misma, como los cinco principios para la coexistencia pacífica integrados al «espíritu de Bandung», los cuales fueron propuestos por Zhou Enlai, primer ministro chino en la década de los 60`s. Otro ejemplo del parentesco de identidades entre el posicionamiento chino y la CSS son los 8 principios ${ }^{4}$, sobre los que se basa la ayuda exterior China (Zhou \& Xiong, 2017). Estos principios han permanecido a través de los planes quinquenales de la RPCh donde exponen de manera explícita sus objetivos y rutas de acción. En la última edición de estos planes, el XIII Plan

\footnotetext{
${ }^{4}$ Estos principios fueron expuestos en 1964 por el ex primer ministro Zhou Enlai, durante sus conversaciones con el ex presidente de Ghana, Kwame Nkrumah: 1. China siempre se ampara en principio de igualdad y beneficio mutuo al proporcionar ayuda a otras naciones 2. China nunca concede ninguna condición o pide ningún privilegio 3. China ayuda a aligerar la carga de los países receptores tanto como sea posible 4. China tiene como objetivo ayudar a los países receptores a lograr gradualmente la autosuficiencia y desarrollo independiente 5. China se esfuerza por desarrollar proyectos de ayuda que requieren menos inversión, pero de resultados más rápidos 6. China proporciona los equipos y materiales de mejor calidad fabricados por ellos mismos 7. Al brindar asistencia técnica, China deberá velar porque el personal del país receptor domine completamente tales técnicas 8 . A los expertos chinos no se les permite hacer ninguna demanda especial o disfrutar de cualquier instalación especial.
}

Revista Brasileira de Políticas Públicas e Internacionais, v.3, n.2, Dezembro/2018, pp. 81-99. 
DOMINGUEZ, Aldo; LO BRUTTO, Giuseppe. Reflexiones en torno a la Nueva Cooperación China para la Transformación Estructural: contrastes y tensiones con el Régimen de Cooperación Internacional para el Desarrollo tradicional.

Quinquenal de China, se propone un nuevo modelo de desarrollo basado en 5 principios: la innovación, la coordinación, sustentable, abierto y desarrollo compartido. Para ello, China plantea una estrategia con dos áreas de acción, la primera conectividad con los países socios, y, la segunda de ellas, promover el cambio estructural de los elementos de producción junto con el apoyo del desarrollo de infraestructura (Lin \& Wang, 2017).

La efectividad en la propuesta para alcanzar el desarrollo hecho por la cooperación para el cambio estructural, se basa en una lógica en la cual, un país debe aprovechar el desarrollo de sus industrias a través de sus ventajas comparativas latentes. Por lo tanto, se obtendrían costos de producción más bajos logrando ser más competitivos en los mercados internos y externos. Esto llevaría a alcanzar mayor participación de mercado, pudiendo obtener mayores ganancias a través de triunfos rápidos, logrando ser más atractivo para la inversión de capitales, y con ello, una mayor propensión al ahorro por parte de la población. Al mismo tiempo la cooperación enfocada al cambio estructural se ha ocupado principalmente de la inversión, capacitación y el comercio como incentivo para el aprovechamiento de las ventajas comparativas. En este proceso, China se ofrece como un acompañante y aliado en el proceso de cambio, poniendo a disposición su experiencia en temáticas de desarrollo sectorial y del mismo cambio estructural. Asimismo, el gigante asiático también se presenta como un inversor debido a su gran demanda de recursos.

A través de la capacitación, inversión y la relación comercial que se genera, China se perfila a encabezar la difusión espacial de innovaciones industriales, es decir, siguiendo el modelo japonés de los Gansos Voladores de Akamatsu ${ }^{5}$, el dragón asiático se posiciona como un líder cooperativo que asume una responsabilidad al trasladar procesos productivos a los

\footnotetext{
${ }^{5}$ La pauta de los «gansos voladores» se refiere a un modelo de desarrollo económico que parte de la competencia industrial que va incorporando nuevos países con bajos salarios para asegurar la prolongación de la cadena industrial de forma similar a los «gansos voladores». Se trata de un modelo de «sector avanzado» que encabeza la difusión espacial de determinadas innovaciones industriales. Este modelo fue propuesto originalmente por Kaname Akamatsu (1961), más tarde dio lugar a distintas versiones (Arrighi, 2007, p. 44).
}

Revista Brasileira de Políticas Públicas e Internacionais, v.3, n.2, Dezembro/2018, pp. 81-99. 
DOMINGUEZ, Aldo; LO BRUTTO, Giuseppe. Reflexiones en torno a la Nueva Cooperación China para la Transformación Estructural: contrastes y tensiones con el Régimen de Cooperación Internacional para el Desarrollo tradicional.

países socios, los cuales, se caracterizarían por ser menos desarrollados y productivos, pero con un interés por el suministro de insumos que representan, puesto que estos países adoptan simultáneamente el papel de socios y clientes.

La estrategia de la RPCh acerca del cambio de la estructura económica mundial ha ido de la mano de su rápido posicionamiento en la economía y política mundial, desde la primera década del siglo XXI. Además, parece haber coincidido con el auge de los gobiernos progresistas (con miras a la izquierda) en la región latinoamericana en la primera década del siglo XX, facilitando el acceso de la RPCh para establecer diálogos políticos, los cuales culminaron en acuerdos comerciales y de cooperación (Lo Brutto \& González, 2015).

Para ilustrar mejor el plan para el cambio estructural, tomando en cuenta las últimas tres décadas del éxito económico chino, encontramos la propuesta del megaproyecto global de «La Nueva Ruta de la Seda», que tiene al Banco Asiático de Inversión en Infraestructura y el Fondo de la Ruta de la Seda como dos de sus mecanismos de financiación. Lo que comenzaba en 2013 como un discurso sobre la revitalización de la antigua ruta de la seda por parte del presidente Xi Jinping, se ha vuelto uno de los mayores retos para la economía mundial, una transformación integral de las infraestructuras de tránsito de mercancías, pasajeros, alta tecnología e hidrocarburos. Se trataría de un plan que colocaría indudablemente a China como el actor económico principal en la esfera mundial.

El megaproyecto chino comprende la creación y desarrollo de corredores económicos, mediante la inversión para vías de comunicación como vías férreas, construcción y ampliación de carreteras, redes eléctricas, líneas de transmisión de datos, puertos, aeropuertos y otras infraestructuras. Asimismo, los chinos buscan incrementar la capacidad de producción industrial de los países que intervienen en la ruta, esto mediante la construcción de parques industriales (Dirmoser, 2017). De esta manera los corredores se convertirían en grandes cadenas internacionales de logísticas y de producción, cuyo objetivo es fortalecer y estrechar los vínculos económicos entre China, Europa y la mayor parte de Asia. Logrando así que

Revista Brasileira de Políticas Públicas e Internacionais, v.3, n.2, Dezembro/2018, pp. 81-99. 
DOMINGUEZ, Aldo; LO BRUTTO, Giuseppe. Reflexiones en torno a la Nueva Cooperación China para la Transformación Estructural: contrastes y tensiones con el Régimen de Cooperación Internacional para el Desarrollo tradicional.

Eurasia se convierta en un meta región interconectada tanto física como económicamente (Dirmoser, 2017). Esta visión y las nuevas propuestas del presidente Xi Jinping, han logrado ganarse la aceptación de países en desarrollo e industriales en Asia y otras partes del mundo.

China ha hecho un buen uso de la publicidad ocasionada por sus inversiones para fomentar una nueva estructura económica en la que se posiciona como líder y director. Mediante la promoción de la cooperación para el cambio estructural, la RPCh consigue dos objetivos importantes, el primero, asegura un suministro de bienes que el país asiático requiere y, por otra parte, genera expectativas positivas por parte del país receptor consolidando los lazos de confianza y asegurándose de esta manera una larga relación.

Si bien parece que la cooperación que otorga China no es desinteresada, esta se dirige al beneficio mutuo y con la única condición de reconocer «una sola China». Posiblemente el uso de las ventajas comparativas sumado a la inversión y relaciones comerciales, se perfilan como la fórmula ganadora que de la mano de la CSS puedan gestar un sistema alternativo de cooperación replanteada desde los conceptos básicos de cooperación y represente un digno contendiente del régimen tradicional de cooperación impulsado por la dinámica Norte-Sur.

\section{La cooperación para el cambio estructural pone en tensión al régimen tradicional de cooperación}

Después de más 60 años de establecerse las bases del régimen de la cooperación actual, donde EE.UU. a través del Comité de Ayuda al Desarrollo (CAD) ha logrado mantenerlo funcional hasta nuestros días, a pesar de las crisis en las que se ha envuelto este sistema, China se presenta con una atractiva propuesta, mostrando un cobijo a los países en desarrollo gracias al posicionamiento hegemónico que posee, así como un trabajo previo de intenso diálogo político con países que no han encontrado el desarrollo prometido en el régimen tradicional. Esto ha logrado que los países en vías de desarrollo se encuentren en una posición cómoda ya que

Revista Brasileira de Políticas Públicas e Internacionais, v.3, n.2, Dezembro/2018, pp. 81-99. 
DOMINGUEZ, Aldo; LO BRUTTO, Giuseppe. Reflexiones en torno a la Nueva Cooperación China para la Transformación Estructural: contrastes y tensiones con el Régimen de Cooperación Internacional para el Desarrollo tradicional.

adquieren una oportunidad para escoger la ayuda que más les sea atractiva y útil, haciéndolas claramente diferenciables al ubicar a sus dos impulsores, los EE.UU. y China.

Lo interesante es observar al gigante asiático como partícipe del régimen tradicional de cooperación promoviendo a la vez su propia cooperación. Muestra de ello es la promesa del dragón asiático de 2 mil millones para ayudar a la implementación de la agenda de los Objetivos del Desarrollo Sostenible (ODS) en la cumbre del Desarrollo Sustentable de las Naciones Unidas, celebrada en Nueva York en el año 2015 (Reuters, 2015). Además, su iniciativa de la «Nueva Ruta de la Seda» incluye cooperación en materia de salud, la cual va alineada al interés señalado por la RPCh para convertirse en un líder de desarrollo, especialmente en el sector salud (Reuters, 2015). De alguna manera este juego doble en el que participa China le ha servido para construir las relaciones geopolíticas necesarias para mantenerse en el camino de posicionamiento. Si bien los dos sistemas recién comienzan a convivir, el régimen tradicional de la AOD se encuentra ante una encrucijada donde requiere de una gran suma de recursos para alcanzar sus objetivos de desarrollo sustentable. De la misma manera vive una contracción de aportaciones a la ayuda por parte de los países donantes tradicionales, los cuales se han visto afectados por el creciente aislacionismo que viene asociado al espíritu proteccionista que se ha extendido alrededor del mundo, sumado a una crisis económica que parece haberse estancado a nivel global y que ha ocasionado que no solo los EE.UU. comiencen a recortar su presupuesto a la ayuda extranjera, sino que también la Unión Europea (U.E.) haya continuado con esta tendencia al disminuir su gasto destinado al desarrollo; mientras que países como Alemania, Italia y Austria han decidido enfocar los presupuestos de ayuda para el desarrollo hacia las crisis migratorias y de refugiados, las cuales consideran como amenazas inminentes para su seguridad nacional. Eso muestra que el contexto actual ha llevado al régimen tradicional a una crisis de contracción de recursos. Sin embrago, nos parece importante señalar que a pesar de esta crisis que vive el sistema de cooperación se ha demostrado mediante la experiencia, que incluso con los innumerables fracasos «técnicos»

Revista Brasileira de Políticas Públicas e Internacionais, v.3, n.2, Dezembro/2018, pp. 81-99. 
DOMINGUEZ, Aldo; LO BRUTTO, Giuseppe. Reflexiones en torno a la Nueva Cooperación China para la Transformación Estructural: contrastes y tensiones con el Régimen de Cooperación Internacional para el Desarrollo tradicional.

este sistema muestra una capacidad de mimetismo, supervivencia y adaptación (Benzi \& Lo Brutto, 2013).

Además, tal como señalan Alonso et al (2018, p.4), el tradicional sistema de cooperación para el desarrollo ha experimentado su propia mutación interna como resultado tanto de la presencia de nuevos actores en su seno (sector privado y países emergentes), que son portadores de concepciones y prioridades diferentes a las propias de los actores tradicionales, como por la dilatación de su perímetro operativo, al ampliarse el repertorio de políticas e instrumentos disponibles.

En este contexto, China ha sabido aprovechar el declive del régimen tradicional de cooperación, a la vez que comenzó a ser un actor más activo del mismo, esto sin disputar abiertamente la supremacía histórica a los EE.UU. Sin embargo, hoy pareciera comenzar a alcanzar mayores cuotas de poder e injerencia lo que le permitiría actuar con mayor decisión. Así, la RPCh estaría ganando credibilidad estratégica con sus aliados en su proyecto de expansión global (Xuetong, 2016). La credibilidad estratégica en el nuevo milenio, se complementa con la estrategia de los 28 caracteres de Deng Xiaoping ${ }^{6}$, estrategia que habría dominado la política de ayuda exterior China de los último 40 años; situación que ha cambiado con el actual presidente Xi Jinping, al posicionarse de manera más agresiva con este tema ${ }^{7}$.

Al mismo tiempo, la RPCh se ha encargado de construir un andamiaje que de soporte a su estrategia y le permita alcanzar sus objetivos de posicionamiento. Un ejemplo sólido de las herramientas que ha creado China es el Banco Asiático de Inversiones en Infraestructura

\footnotetext{
${ }^{6}$ Deng Xiaoping incorporó inicialmente cinco principios directrices en 1989 (conocidos como «24 caracteres») que se extendieron a seis en 1993 («28 caracteres») y que se traducen como: observar y analizar los acontecimientos internacionales con calma, asegurar nuestra posición, ocultar nuestras capacidades y esperar el momento adecuado, ser buenos en mantener un perfil bajo, nunca liderar la reivindicación y llevar a cabo oposición de carácter medido (Moncada, 2007, pág. 7).

${ }^{7}$ La teoría del realismo moral es la cobertura ideológica de la nueva doctrina de política exterior asertiva de «lucha por el éxito» con la que el nuevo presidente Xi Jinping, en el contexto del «gran renacimiento de la nación china», sustituyó en 2013 a la anterior de «mantener un perfil bajo» de 1978 (completada en 2004 con la doctrina del desarrollo pacífico).
}

Revista Brasileira de Políticas Públicas e Internacionais, v.3, n.2, Dezembro/2018, pp. 81-99. 
DOMINGUEZ, Aldo; LO BRUTTO, Giuseppe. Reflexiones en torno a la Nueva Cooperación China para la Transformación Estructural: contrastes y tensiones con el Régimen de Cooperación Internacional para el Desarrollo tradicional.

(BAII), fundado en octubre de 2014 con un capital de 100 mil millones de dólares, de los cuales el gigante asiático aportó la mitad y el resto puesto por 56 socios de los cuales 18 son europeos, 3 africanos y Brasil (Domínguez, 2016). El BAII tiene como misión estimular la cooperación financiera dentro de la región, así como el financiamiento de proyectos de infraestructura en Asia. De esta manera el BAII proporciona a China la plataforma necesaria para exportar capital, ayuda técnica y mano de obra hacia las economías emergentes de Asia. Esto no quiere decir que el BAII es de apoyo exclusivo para países del continente asiático, al contrario, en el 2017, 10 países fuera de la región asiática se han unido a este; en el último año la adhesión fue principalmente por países de América Latina en vías de desarrollo, aspecto que cuestiona la posición del régimen tradicional de cooperación como eje rector de la cooperación. Por otro lado, la RPCh cuenta con el Banco de Desarrollo de China (BDC), el banco de desarrollo más grande del mundo, que, junto a la agencia de crédito a la exportación, China Eximbank, han conformado su brazo financiero. El cual le ha permitido ejecutar el dialogo político dentro de la CSS con respecto a Asia durante las Cumbres Asean-China desde 1996, en África mediante el Foro de Cooperación África-China (FOCAC) desde el año 2000 y recientemente en América Latina (I Foro de Cooperación Celac-China en 2015), (Domínguez, 2016). Para magnificar la capacidad de esta dupla institucional se puede mencionar que solo en América Latina, estas dos gigantescas instituciones asiáticas proveyeron entre 2005 y 2014 la cantidad de 199, 000 millones de dólares, cantidad superior a la dada por el Banco Mundial, US Eximbank y el Banco Interamericano de Desarrollo (BID) juntos (Domínguez, 2016). El Banco Asiático de Inversiones en Infraestructura junto con el Fondo para la Ruta de la Seda, han sido los principales medios de financiamiento de la Nueva Ruta de la Seda, barco en el que nadie quiere quedarse fuera, y llevando de esta manera a los países a replantearse el obtener parte de beneficios de la estrategia china.

Otra de las particularidades que pone en tensión el régimen tradicional de cooperación es el acercamiento que han tenido los países en vías de desarrollo a la propuesta china de cooperación. Esto porque la AOD a través del CAD enfrenta una atadura conceptual de la

Revista Brasileira de Políticas Públicas e Internacionais, v.3, n.2, Dezembro/2018, pp. 81-99. 
DOMINGUEZ, Aldo; LO BRUTTO, Giuseppe. Reflexiones en torno a la Nueva Cooperación China para la Transformación Estructural: contrastes y tensiones con el Régimen de Cooperación Internacional para el Desarrollo tradicional.

ayuda, una limitación para seleccionar la herramienta más conveniente para impulsar el desarrollo debido a la estricta definición de los mecanismos oficiales. Además, que el aceptar AOD implica un compromiso para realizar cambios estructurales en los países receptores a petición de recomendaciones de la Organización para la Cooperación y el Desarrollo Económico (OCDE). Mientras que la cooperación ofertada por China ofrece principalmente créditos a la exportación, inversiones en infraestructura y condiciones favorables para el intercambio comercial, sin que esto signifique alguna atadura para el receptor más allá de la misma deuda; lo cual se sustenta una vez más en la idea china de no interferencia y solicitando únicamente la aceptación de una sola China. Muestra de ello, son las exorbitantes cantidades invertidas por parte de China con respecto América Latina y África, países con los cuales teje y consolida su nueva estructura económica, asegurando así, el suministro de bienes primarios y la expansión de su acceso a mercados para comercializar.

Sin embargo, estás prácticas no han sido asimiladas de buena manera por todos los observadores, ya que la dinámica propuesta por China se ha ganado adjetivos neocolonialistas y el nombre de «Consenso de Beijing» (Fanjul, 2011), relacionándolas a prácticas neocolonialistas donde China ofrece un vínculo de cooperación entre países en vías de desarrollo, pero se cree que en el trasfondo se estimula la dependencia y los patrones de subordinación característicos de las relaciones centro-periferia (Slipak, 2014).

De la misma forma el régimen tradicional de cooperación ha mostrado una reacción de anticipo ante el gran volumen de financiamiento que estaría generando la RPCh para los rubros de asistencia extranjera e inversión. La propuesta del CAD fueron los Total Official Support for Sustainable Development (TOSSD) en diciembre del 2014 en el que se amplía la conceptualizad del desarrollo y los mecanismos de la $\mathrm{AOD}^{8}$, y que están obligando una reforma

\footnotetext{
${ }^{8}$ La modernización de la AOD y el nuevo concepto de TOSSD, propuestos en 2014, y la ampliación del club a los proveedores emergentes para incorporarlos a la nueva institucionalidad aparentemente más incluyente de la Alianza Global para la Cooperación Eficaz al Desarrollo (2012) son el reflejo de esta nueva estrategia que pone de relievo las inconsistencias históricas y contradicciones internas del régimen internacional de ayuda.
}

Revista Brasileira de Políticas Públicas e Internacionais, v.3, n.2, Dezembro/2018, pp. 81-99. 
DOMINGUEZ, Aldo; LO BRUTTO, Giuseppe. Reflexiones en torno a la Nueva Cooperación China para la Transformación Estructural: contrastes y tensiones con el Régimen de Cooperación Internacional para el Desarrollo tradicional.

en profundidad del sistema de cooperación para el desarrollo (Alonso et al, 2018, p.5). El CAD ante la incapacidad de alcanzar una vez más su renovados ODS los cuales requieren de grandes cantidades de financiamiento para alcanzarse, ha optado por incluir mecanismos de cooperación propuestos por la CSS como todo el crédito público comercial o concesional con propósitos de desarrollo o para la financiación de bienes públicos globales que se consideran habilitadores del mismo (paz, seguridad, cambio climático), (Domínguez, 2016). Con esta propuesta, el CAD llega a una crisis de identidad (Domínguez, 2011), en la que ha tenido que recurrir a una imitación de la métrica de la CSS que lleva a recordar una industria en rezago. Sin embargo, consideramos que no se espera que sea el fin del CAD ya que aún tiene planes de intentar sostenerse a través de la cooperación o generar mejores proyecciones con la incorporación de China al Centro de Desarrollo de la OCDE en julio de 2015 (Domínguez, 2016). Efectivamente como señalan Alonso et al (2018) la propuesta de reforma del CAD está enmarcada en restaurar la credibilidad de la AOD; reportar de forma integrada los recursos en apoyo de las estrategias de desarrollo sostenible; movilizar más y mejores recursos públicos y privados para el desarrollo sostenible incrementando de esta manera el impacto de la cooperación para el desarrollo; avanzar en la transparencia y la rendición de cuenta con sólidos estándares en cuanto a la financiación al desarrollo.

En este sentido, si bien es posible (y deseable) que en el largo plazo la función del CAD-OCDE se «desvanecerá», o que “al menos su papel protagónico en cuestiones de ayuda y cooperación al desarrollo” se verá reducido (Tandon, 2009: 228), es improbable que esto ocurra en el corto y hasta mediano plazo (Benzi \& Lo Brutto, 2013:228).

En este contexto, la RPCh continúa fortaleciendo su credibilidad estratégica apuntando hacia un nuevo orden internacional, multipolar y más justo, intentado dar paso a un multilateralismo competitivo (Stuenkel, 2017, p.240) que más que generar rupturas con el actual orden económico y político global liderado por Estados Unidos podría generar competencia en el orden global haciendo de esta manera convivir ambos sistemas.

Revista Brasileira de Políticas Públicas e Internacionais, v.3, n.2, Dezembro/2018, pp. 81-99. 
DOMINGUEZ, Aldo; LO BRUTTO, Giuseppe. Reflexiones en torno a la Nueva Cooperación China para la Transformación Estructural: contrastes y tensiones con el Régimen de Cooperación Internacional para el Desarrollo tradicional.

\section{Conclusiones}

A lo largo de este texto se pueden observar las tensiones que el nuevo régimen de CSS chino pone al tradicional sistema de ayuda al desarrollo. No cabe duda que en este contexto China despierta un enorme interés en la comunidad internacional, ya sea por su riqueza cultural, su gran tamaño o su acelerado crecimiento económico y posicionamiento político en el ámbito global intensificando su participación en las dinámicas hegemónicas e impulsando la estrategia de generar una nueva estructura económica. La estrategia de los 28 caracteres y su política de credibilidad estratégica son un claro ejemplo de ello. En este sentido, hoy en día es imposible negar el peso político y económico del gigante asiático, por lo cual, en 2013 y ratificado en 2017, su líder Xi Jinping ha propuesto cambiar la estrategia a una lucha por el éxito en el marco del Sueño Chino 9 . Una propuesta de aspecto más agresivo, pero sin llegar a confrontar de manera abierta la hegemonía de los Estados Unidos y con el fin de lograr la creación de nuevo régimen internacional de CSS (Domínguez, 2016). Un nuevo régimen, que tal como señala Domínguez (2018) necesitará impulsar y afianzar los tres pilares fundamentales en el que se está sustentando, es decir, la institucionalidad en el plano financiero, el development compact ${ }^{10}$ y la financiarización amplia del desarrollo, y, el sistema de monitoreo y evaluación. Con ello, el gigante asiático se afianzará a nivel global como el nuevo líder y arquitecto del nuevo régimen internacional de CSS ejerciendo muchísima presión en el tradicional sistema de cooperación internacional. Además, su nueva estrategia de striving for achievement respondería a este momento de transición hegemónica.

\footnotetext{
${ }^{9}$ Comportaría también evitar la llamada «trampa de Tucídides» por medio de la cooperación internacional, es decir, de esta forma se tratará de evitar aquella situación donde una potencia hegemónica en declive enfrenta y desafía abiertamente a la competencia de una hegemón emergente.

${ }^{10}$ Señala Domínguez (2018, p.62) que es el concepto que da coherencia a la cooperación de India, y que ha ganado rápidamente aceptación en Naciones Unidas como nueva métrica.
}

Revista Brasileira de Políticas Públicas e Internacionais, v.3, n.2, Dezembro/2018, pp. 81-99. 
DOMINGUEZ, Aldo; LO BRUTTO, Giuseppe. Reflexiones en torno a la Nueva Cooperación China para la Transformación Estructural: contrastes y tensiones con el Régimen de Cooperación Internacional para el Desarrollo tradicional.

Si bien China navega con una propaganda de paz y desarrollo, es innegable ver la manera en que organiza a sus aliados, construye instituciones y mecanismos de cooperación y dirige su economía hacia sí mismo. El análisis de estas prácticas le han valido el adjetivo de neocolonialistas por los críticos de esta cooperación, debido a que la RPCh obtiene bienes básicos de los países que invierte y a la vez vende productos de valor agregado de vuelta, acciones que nos recuerdan a la estructura centro- periferia de la dinámica Norte-Sur.

La RPCh a lo largo de su historia ha mantenido relaciones de cooperación y comercialización con países de América Latina y África, pero fue la CSS quien le permitió solidificar los lazos con cada uno de los países de estos continentes con las cuales mantiene una fuerte relación en la actualidad. A través de estas, China se ha visto beneficiada al ganar interés sobre sus propuestas y con el tiempo, ganar nuevos socios. Países de estas regiones, que en algún momento formaron parte del movimiento contra hegemónico, ya sea perteneciendo al G77 o también a la reunión del Movimiento de los Países No Alineados, encuentran una nueva esperanza de ver logrado estos objetivos los cuales fueron olvidados a causa de la crisis de la deuda de los años 80’s ocasionada por los países del norte y por la implementación en el marco del sistema de ayuda al desarrollo del Plan de Buenos Aires que prácticamente inauguró la era neoliberal del régimen de cooperación internacional. Por lo tanto, esta afinidad con el Sur global encaja perfectamente con el plan de una nueva estructura económica de China, pero que aún no asegura un cambio de realidades en la posición de estos países en vías de desarrollo. En este sentido, señalamos como la misma China continúa siendo clasificada por los principales organismos internacionales como un país en vía de desarrollo, sobre todo cuando se observa su PIB per cápita, que, por ejemplo, en 2016 la ubican en el puesto 76 de entre 196 países (Banco Mundial, 2018).

Mientras tanto la AOD se pone en tensión llegando a ser sólo complementaria para algunos países que encuentran mejor cobijo en la RPCh, al no tener que comprometer su soberanía a causa de las reformas requeridas por la OCDE. En este contexto, podemos concluir

Revista Brasileira de Políticas Públicas e Internacionais, v.3, n.2, Dezembro/2018, pp. 81-99. 
DOMINGUEZ, Aldo; LO BRUTTO, Giuseppe. Reflexiones en torno a la Nueva Cooperación China para la Transformación Estructural: contrastes y tensiones con el Régimen de Cooperación Internacional para el Desarrollo tradicional.

que, aunque el nuevo régimen de cooperación Sur-Sur que China está impulsando genera tensiones y contrastes al tradicional régimen de cooperación, este último no morirá pronto y menos a causa de su reciente transformación con la incorporación de los TOSSD, que no pretenden suplir a la AOD, pero si reduciría su diferenciación con la CSS, como productos en el mercado de la cooperación.

De esta forma, los países ahora pueden encontrar financiamiento para una gran cantidad de objetivos sin entender plenamente hacia dónde va ese sistema y cuál sería el costo de estas nuevas formas de financiamiento. Por lo tanto, la búsqueda del desarrollo queda otra vez ante una encrucijada, es decir, si seguir con las lógicas Norte en el club de Occidente o por el contrario buscar una nueva forma de desarrollo hacia el Sur y bajo un liderazgo Oriental.

\section{Referencias}

Alonso, J.A., (Dir.), Aguirre, P., Santander, G., (2018), La nueva métrica de la financiación para el desarrollo: el apoyo oficial total para el desarrollo sostenible (AOTDS/TOSSD) y su aplicación a España, Ministerio de Asuntos Exteriores y de Cooperación (MAEC) Secretaría de Estado de Cooperación Internacional y para Iberoamérica y el Caribe, Dirección General de Políticas de Desarrollo Sostenible, Fundación Internacional y para Iberoamérica de Administración y Políticas Públicas (FIIAPP).

Arrighi, G. (2007). Adam Smith en Pekín, Orígenes y fundamentos del siglo XXI. Madrid: Ediciones Akal.

Banco Mundial (2018). PIB per cápita (US \$ a precios actuales). Recuperado 10 de enero de 2018. De Banco Mundial: https://datos.bancomundial.org/indicador/NY.GDP.PCAP.CD?end=2016\&locations=CN\&nam $\underline{\text { e_desc }=\text { false } \& \text { start }=1960 \& v i e w=\text { chart }}$

Revista Brasileira de Políticas Públicas e Internacionais, v.3, n.2, Dezembro/2018, pp. 81-99. 
DOMINGUEZ, Aldo; LO BRUTTO, Giuseppe. Reflexiones en torno a la Nueva Cooperación China para la Transformación Estructural: contrastes y tensiones con el Régimen de Cooperación Internacional para el Desarrollo tradicional.

Benzi, D. \& Lo Brutto, G., 2013. La cooperación Sur-Sur en América Latina a principios del siglo XXI (un enfoque menos indulgente). Em: Volver al desarrollo o salir de él. Límites y potencialidades del cambio desde América Latina. Puebla, México: EyC, pp. 217-250.

Dirmoser, D., 2017. La Gran Marcha china hacia el oeste: El megaproyecto de la nueva Ruta de la Seda. Nueva Sociedad, Issue 270, pp. 27-38.

Domínguez, R., 2011. La crisis de identidad del sistema de ayuda.. [Online] Available at: http://www.ciberoamericana.com/pdf/NPFC_Dominguez_Mayo11.pdf [Acesso em 10 Enero 2018].

Domínguez, R., 2016. Cooperación financiera para el desarrollo, ADN de la cooperación SurSur. Iberoamerican Journal of Development Studies, pp. 62-86.

Domínguez, R., 2017. La Princesa y el Dragón: Cooperación China en América Latina y más allá. Revista Internacional de Cooperación y Desarrollo, pp. 3-27.

Fanjul, E., 2011. El <<Consenso de Beijing>>: Universalidad y particularidad del modelo chino. La nueva geogragía de la internacionalización, pp. 47-53.

Lo Brutto, G. \& González, C., 2015. La influencia China en la Cooperación Sur-Sur Latinoamericana, durante la segunda década del Siglo XXI, Santander, España: Cátedra de Cooperación Internacional con Iberoamérica.

Moncada, M., 2007. "Visión del mundo exterior de las cuatro generaciones de líderes políticos de la República Popular de China: evolución histórica y conceptual. Documentos CIDOB - Asia 27, Mayo.pp. 1-14.

Reuters, A., 2015. La Jornada: Creará China fondo para contribuir al desarrollo sostenible de países emergentes.

[Online]

Available at: http://www.jornada.unam.mx/2015/09/27/economia/025n2eco

Revista Brasileira de Políticas Públicas e Internacionais, v.3, n.2, Dezembro/2018, pp. 81-99. 
DOMINGUEZ, Aldo; LO BRUTTO, Giuseppe. Reflexiones en torno a la Nueva Cooperación China para la Transformación Estructural: contrastes y tensiones con el Régimen de Cooperación Internacional para el Desarrollo tradicional.

Slipak, A., 2014. América Latina y China: ¿cooperación sur-sur o <<consenso de Beijing>>?. Nueva Sociedad, pp. 102-113.

Xuetong, Y., 2016. Political Leadership and Power Redistribution. The Chinese Journal of International Politics, 9(1), pp. 1-26.

Yifu Lin, J. \& Wang, Y., 2017. Going Beyond Aid: Development Cooperation for Structural Transformation. United Kingdom: Cambridge University Press.

Zhou, H. \& Xiong, H., 2017. China's Foreing Aid: 60 Years in Retrospect. Singapore: SSAP y SPRINGER.

Revista Brasileira de Políticas Públicas e Internacionais, v.3, n.2, Dezembro/2018, pp. 81-99. 